\title{
PENGARUH SUPERVISI KEPALA RUANGAN TERHADAP PELAKSANAAN PENDOKUMENTASIAN ASUHAN KEPERAWATAN DI RUANG RAWAT INAP RSU AISYIYAH PADANG TAHUN 2018
}

\author{
Asmawati $^{1}$, Yuanita Ananda ${ }^{2}$, Alkafi $^{3}$ \\ ${ }^{1}$ Program Studi Keperawatan, STIKes Alifah Padang Jln. Khatib Sulaiman No. 52 B,Indonesia \\ Email: wati.as45@yahoo.com \\ ${ }^{2}$ Program Studi Keperawatan, STIKes Alifah Padang, Jln. Khatib Sulaiman No. 52 B,Indonesia \\ Email:yuanita_ananda88@yahoo.com \\ ${ }^{3}$ Program Studi Kesehatan Masyarakat, STIKes Alifah Padang, Jln. Khatib Sulaiman No. 52 B,Indonesia \\ Email: alkafi01@gmail.com
}

\begin{abstract}
Abstrak
Supervisi dalam pelaksanaan pendokumentasian asuhan keperawatan di RSU 'Aisyiyah Padang didapatkan data berdasarkan hasil pengamatan medical record di ambil 40 sampel dokumentasi rekam medik pasien rawat inap, hanya 21 dokumen (42\%) yang dokumentasi asuhan keperawatan terisi lengkap,19 dokumen (58\%) di isi tidak lengkap. Hasil wawancara dengan kepala Instalasi Rawat Inap mengenai kegiatan supervisi kepala ruang tentang dokumentasi asuhan keperawatan, diperoleh informasi bahwa selama ini kepala ruangan melakukan supervisi sekali sebulan. Penelitian ini bertujuan untuk mengetahui Pengaruh Supervisi Kepala Ruangan Terhadap Pelaksanaan Pendokumentasian Asuhan Keperawatan di Ruang Rawat Inap RSU 'Aisyiyah Padang Tahun 2018. Jenis penelitian adalah Preeksperimental design dengan rancangan One Group pretest-Postest Design dengan jumlah sampel 12 orang diambil secara total sampling. Uji statistik Paired T-test didapatkan perbedaan pendokumentasian asuhan keperawatan sebelum dan sesudah diberikan supervisi, dimana rata-rata pendokumentasian asuhan keperawatan sebelum diberikan supervisi 34,56 standar deviasi 4,912 yaitu tergolong tidak lengkap. Sesudah diberikan supervisi rata-rata pendokumentasian asuhan keperawatan menjadi 28,38 dengan standar deviasi 4,773 atau tergolong lengkap. Berdasarkan hasil uji statistik didapatkan P value $=0,000$.
\end{abstract}

Kata kunci : Supervisi, Pendokumentasian Asuhan Keperawatan

\section{Abstract}

Supervision in the implementation of documentation of nursing care at RSU 'Aisyiyah Padang obtained data based on medical record observations taken 40 documentation samples of medical records of inpatients, only 21 documents (42\%) with complete nursing care documentation, 19 documents (58\%) in incomplete content. Based on the interview with the head of the Inpatient Installation regarding the supervision of the head of the room about nursing care documentation, information was obtained that so far the head of the room had supervised once a month. This study aims to determine the influence of the Supervision of the Head of the Room on the Implementation of Documentation of Nursing Care in the Inpatient Room of RSU 'Aisyiyah Padang in 2018. This type of research is Pre-experimental design used by One Group pretest-Postest Design. With a sample of 12 people with total sampling technique. Analysis of bivariate analysis statistical tests used statistical tests Paired T-test with $p$ value (0.05) result there is differences in documenting nursing care before and after supervision, where the average documentation of nursing care before being given supervision 34.56 standard deviation 4,912 is classified as incomplete. After being supervised on average, documenting nursing care became 28.38 with a standard deviation of 4,773 or complete. Based on the results of statistical tests obtained P value =0,000.

Keywords: Supervision, Documentation of Nursing Care

\section{PENDAHULUAN}

Manajemen keperawatan adalah terlaksananya asuhan keperawatan yang bermutu kepada pasien. Pelaksanaan menajemen keperawatan didukung kemampuan dan keterampilan kepemimpinan dalam pelayanan keperawatan yang efektif dan efisien oleh setiap perawat apakah sebagai staf, ketua tim, kepala ruang, pengawas atau kepala bidang (Swansburg, Rc.2000).

Setiap pelaksanaan proses keperawatan, perawat akan selalu melakukan pencatatan atau sering disebut pendokumentasian, mulai dari pengkajian, 
diagnosa, perencanaan, pelaksanaan dan evaluasi. Dokumentasi merupakan aspek penting dari praktik keperawatan karena berisi catatan-catatan yang berguna untuk komunikasi, tagihan finansial, edukasi, pengkajian, riset, audit dan dokumentasi legal (Potter \& Perry, 2005).

Pelaksanaan supervisi bukan hanya ditujukan untuk mengawasi apakah seluruh staf keperawatan menjalankan tugasnya dengan sebaik-baiknya, sesuai dengan instruksi atau ketentuan yang telah digariskan, tetapi juga bagaimana memperbaiki proses keperawatan yang sedang berlangsung. Melaksanakan peran perawat dalam memberikan asuhan keperawatan kita akan dapat melihat kinerja perawat melalui pengamatan langsung yaitu proses pemberian asuhan keperawatan atau catatan pasien (dokumentasi) asuhan keperawatan yang telah diberikan.

Penelitian yang dilakukan oleh Pribadi (2009) tentang pelaksanaan dokumentasi asuhan keperawatan yang didapatkan hasil bahwa pelaksanaan dokumentasi asuhan keperawatan di RSUD Kelet Jepara dalam kategori baik 58,1\% dan kategori tidak baik 41,9\%. Perawat dalam melaksanakan tugas sehari-hari dipimpin oleh seorang kepala ruang. Kaitannya dengan pendokumentasian asuhan keperawatan tersebut, kepala ruangan memiliki tugas untuk memberikan pendampingan/supervisi terhadap anggota ruangannya karena sebagian besar hasil dari audit dokumentasi masih kurang dari nilai 75 (Keliat, 2012).

Sedang hasil penelitian Farida (2001) tentang hubungan supervisi kepala ruangan dengan pelaksanaan proses keperawatan yang menyatakan supervise kepala ruangan berhubungan bermakna dengan pelaksanaan proses keperawatan di RS Jantung Harapan kita, dengan $\mathrm{P}=0,04$. Manurung (2004) juga mengatakan bahwa ada hubungan yang bermakna antara supervisi kepala ruangan dengan pendokumentasian asuhan keperawatan di RS PGI Cikini Jakarta, dengan $\mathrm{P}=0,003$.

Salah satu upaya untuk meningkatkan pelaksanaan pendokumentasian asuhan keperawatan yaitu dengan supervisi yang dilakukan oleh kepala ruangan atau pimpinan Rumah Sakit. Kegiatan supervisi yang baik tidak terlepas dari kemampuan seorang manajer (kepala ruangan ) dalam melakukan bimbingan, arahan serta memotivasi karyawannya dalam kegiatan,termasuk dalam kegiatan supervisi yang dapat dilihat dari model supervisi yang dilakukan kepala ruang yang dapat di lihat dari kemampuan struktur, skills, support dan sustainability kepala ruangan(Sitorus,2011).
Menurut

Arwani

(2006),

memberikan pengarahan dan petunjuk yang jelas sehingga dapat dimengerti oleh staf dan pelaksana keperawatan, memberikan saran, nasehat dan bantuan kepada staf dan pelaksanaan keperawatan,memberikan motivasi untuk meningkatkan semangat kerja, memberikan latihan dan bimbingan yang diperlukan oleh pelaksanan keperawatan, melakukan penilaian terhadap penampilan kinerja perawat, mengadakan agar asuhan keperawatan yang diberikan lebih baik. Supervisi dapat dilakukan dengan dua cara yaitu supervisi langsung dan tidak langsung. Perawat menejer tingkat unit atau kepala ruangan melakukan tugas pengawasan atau supervisi kepada staf dalam pelayanan asuhan keperawatan mulai dari pengkajian, diagnosa keperawatan, perencanaan, implementasi, evaluasi serta pendokumentasian dengan baik (Supratman,2008).

Di RSU 'Aisyiyah Padang didapatkan data berdasarkan hasil pengamatan bahwa, komite keperawatan bekerja berdasarkan SK Direktur dan berada di bawah koordinasi bidang pelayanan medik dan keperawatan. Supervisi terhadap pelayanan keperawatan di rawat inap dilakukan oleh kepala Ruangan. Kepala ruangan sebagai supervisor belum melakukan peran bimbingan secara optimal, kegiatan supervisi di ruangan lebih berfokus pada pengawasan terhadap pendokumentasian. Dilihat dari semua format dokumentasi asuhan Keperawatan RSU 'Aisyiyah Padang terisi dengan lengkap. Dari hasil medical record di ambil 40 sampel dokumentasi rekam medik pasien rawat inap, hanya 21 dokumen (42\%) yang dokumentasi asuhan keperawatan terisi lengkap,19 dokumen (58\%) di isi tidak lengkap.

Dan hasil pengamatan di ruang rawat inap dokumentasi asuhan keperawatan terisi , Pengkajian 47\%, diagnosa keperawatan 54\%, Perencanaan $47 \%$, tindakan keperawatan 49 $\%$ dan evaluasi $50 \%$. Dari data tersebut tampaklah pelaksanaan dokumentasi asuhan keperawatan masih rendah $(49,5 \%)$. Sedangkan yang ditetapkan Depkes $80 \%$, hal ini menunjukan asuhan keperawatan yang berkesinambungan belum terlaksana dengan baik.

Berdasarkan wawancara dengan 8 orang perawat pelaksana diruang rawat inap RSU 'Aisyiyah Padang yang kurang tepat menjawab pertanyaan mengenai tujuan utama dan pentingnya pendokumentasian asuhan keperawatan. Namun secara umum perawat tersebut mengetahui bahwa pendokumentasian asuhan keperawatan tersebut harus di lengkapi dalam pengisian. 
Tetapi mereka beralasan bahwa pekerjaan mencatat asuhan keperawatan di rasakan cukup membebani, meskipun pada kenyataan jumlah perawat pelaksana masih berimbang di lihat dari Bed Occupancy Rate. Dan juga berdasarkan hasil pengamatan diruang perawat kerjanya lebih banyak mengobrol dari pada membuat asuhan keperawatan.

Berdasarkan wawancara dengan kepala Instalasi Rawat Inap mengenai kegiatan supervisi kepala ruang tentang dokumentasi asuhan keperawatan, diperoleh informasi bahwa selama ini kepala ruangan melakukan supervisi sekali sebulan. Supervisi yang dilakukan tidak direncanakanya, serta tidak adanya evaluasi terhadap supervisi yang di lakukan. Perawat menganggap supervisi lebih di fokuskan pada masalah teknis dalam implementasi pelayanan asuhan keperawatan. Sehingga perawat lebih menekankan kepada implementasi keperawatan karena mereka merasa hal tersebut yang lebih di perhatikan oleh kepala ruang. Dan ada juga beberapa perawat mengatakan supervisi dilakukan terlalu singkat 1 - 3 menit, tidak ada evaluasi terhadap apa yang di supervisi.

Berdasarkan fenomena tersebut peneliti ingin mengetahui "Pengaruh Supervisi Kepala Ruangan Terhadap Pelaksanaan Pendokumentasian Asuhan Keperawatan di Ruang Rawat Inap RSU 'Aisyiyah Padang Tahun 2018". Melalui penelitian ini akan diketahui apakah ada Pengaruh Supervisi Kepala Ruangan Terhadap Pelaksanaan Pendokumentasian Asuhan Keperawatan di Ruang Rawat Inap RSU 'Aisyiyah Padang Tahun 2018

\section{METODE PENELITIAN}

Penelitian ini telah dilakukan pada bulan Mei sampai Agustus 2018 di RSU Aisyiah Padang. Jenis penelitian ini adalah penelitian Pre-eksperimental design dengan rancangan yang digunakan One Group pretest-Postest Design. Populasi dalam penelitian ini adalah seluruh perawat pelaksana di instalasi Rawat Inap RSU 'Aisyiyah Padang sebanyak 12 orang. Sampel dari penelitian adalah perawat pelaksana yang bekerja di Instalasi Rawat Inap RSU 'Aisyiyah Padang. Teknik pengambilan sampel dalam penelitian ini adalah sampel jenuh. Teknik pengumpulan data yang dipergunakan dalam penelitian ini yaitu pengumpulan data primer. Penelitian ini menggunakan analisis Univariat dan analisis bivariat dengan uji statistik Paired $T$ test

\section{HASIL DAN PEMBAHASAN}

\section{Analisa Univariat}

Table 1.1

Distribusi Rata-rata Perkembangan Pelaksanaan Pendokumentasian Asuhan Keperawatan di Ruang Rawat Inap RSU Aisyiah Padang Sebelum Diberikan Supervisi Tahun 2018

\begin{tabular}{llllll}
\hline Variabel & N & Mean & SD & $\begin{array}{c}\text { Nilai } \\
\text { Min }\end{array}$ & $\begin{array}{c}\text { Nilai } \\
\text { Max }\end{array}$ \\
& & & & & \\
\hline $\begin{array}{l}\text { Pendokum } \\
\text { entasian } \\
\text { asuhan } \\
\text { keperawata }\end{array}$ & 12 & 34,56 & 4,912 & 20 & 32 \\
$n$ & & & & & \\
& & & & & \\
& & & & & \\
\end{tabular}

Berdasarkan tabel 1.1 terlihat bahwa dari 12 responden perawat sebelum diberikan supervisi, rata-rata perkembangan pendokumentasian asuhan keperawatan sebesar 34,56 dengan standar deviasi 4,912. Selanjutnya terlihat nilai minimum 20 tergolong pendokumetasian tidak lengkap dan nilai maximum 32 tergolong pendokumentasian lengkap.

Hasil penelitian ini sejalan dengan penelitian yang dilakukan oleh Silawati (2014). Hasil penelitian menunjukkan bahwa pelaksanaan dokumentasi asuhan keperawatan sebelum diberikan supervisi sebagian besar (69\%) tidak lengkap.

Menurut Keliat (2012) supervisi adalah proses pengawasan terhadap pelaksanaan kegiatan untuk memastikan apakah kegiatan tersebut berjalan sesuai tujuan organisasi dan standar yang telah ditetapkan. Supervisi dilakukan oleh orang yang memiliki kemampuan yang cakap dalam bidang yang disupervisi. Supervisi biasanya dilakukan oleh atasan terhadap bawahan atau konsultan terhadap pelaksana.

Berdasarkan analisis peneliti sebelum dilakukan supervisi sebagian besar pendokumentasian asuhan keperawatan tidak lengap, Pada awalnya sangat sulit untuk melakukan supervisi terhadap pendokumentasian asuhan keperawatan akan tetapi berkat bantuan orang terdekat atau pendampingnya untuk memperkenalkan supervisi sebagian perawat mulai mengerti akan pentingnya supervisi terhadap pendokumentasian asuhan keperawatan. Perawat mulai membuat pendokumentasian sesuai dengan standar yang ada walaupun masih belum lengkap. Ini sesuai dengan teori Arwani ,(2003) bahwa sebagai seorang supervisor kepala ruang harus mempunyai kemampuan/ kompetensi untuk memberikan 
latihan dan bimbingan. Di samping itu sebagai supervisor kepala ruang harus memiliki pengetahuan dan keterampilan yang cukup untuk jenis pekerjaan yang akan di supervisi

Table 1.2

Distribusi Rata-rata Perkembangan Pelaksanaan Pendokumentasian Asuhan Keperawatan di Ruang Rawat Inap RSU Aisyiah Padang Setelah Diberikan Supervisi Tahun 2018

\begin{tabular}{lccccc}
\hline \multicolumn{1}{c}{ Variabel } & N & Mean & SD & $\begin{array}{c}\text { Nilai } \\
\text { Min }\end{array}$ & $\begin{array}{c}\text { Nilai } \\
\text { Max }\end{array}$ \\
\hline $\begin{array}{l}\text { Pendokumentasia } \\
\text { n asuhan } \\
\text { keperawatan }\end{array}$ & 12 & 28,38 & 4,77 & 21 & 38 \\
\hline
\end{tabular}

Berdasarkan tabel 1.2 dari 12 responden perawat setelah diberikan supervisi , rata-rata perkembangan pendokumentasian asuhan keperawatan sebesar 28,38 dengan standar deviasi 4,773 Selanjutnya terlihat nilai minimum 21 tergolong pendokumetasian lengkap dan nilai maximum 38 tergolong pendokumentasian lengkap

Hasil penelitian ini sejalan dengan penelitian yang dilakukan oleh Wirawan (2015). Hasil penelitian menunjukkan bahwa pelaksanaan dokumentasi asuhan keperawatan setelah diberikan supervisi sebagian besar (80\%) lengkap.

Supervisi terhadap kinerja perawat pelaksana dalam pendokumentasian asuhan keperawatan dapat dilakukan dengan memberikan bimbingan, pengarahan, observasi dan pemberian motivasi serta evaluasi terhadap pendokumentasian tiaptiap tahap proses keperawatan. Kelengkapan dan kesesuaian dengan standar merupakan variabel yang harus disupervisi (Wiyana, 2008).

Menurut Arwani (2003) bahwa sebagai seorang supervisor kepala ruang harus mempunyai kemampuan/kompetensi untuk memberikan latihan dan bimbingan . Di samping itu sebagai supervisor kepala ruang harus memiliki pengetahuan dan keterampilan yang cukup untuk jenis pekerjaan yang akan di supervisi. Dilihat dari peran supervisor tanggung jawab utama seorang supervisor adalah mencapai hasil sebaik mungkin dengan mengkoordinasikan system kerjanya. Para supervisor mengkoordinasikan pekerjaan karyawan dengan mengarahkan, melancarkan, membimbingan, memotivasi, dan mengendalikan (Dharma, 2003).

Menurut asumsi peneliti terhadap penelitian ini adalah bahwa kegiatan supervisi dapat meningkatkan pelaksanaan pendokumentasian asuhan keperawatan.

Tabel 1.3

Perbedaan Pendokumentasian Asuhan Keperawatan di Ruang Rawat Inap RSU Aisyiah Padang Sebelum dan Sesudah diberikan Supervisi di Ruang Rawat Inap RSU Aisyiah Padang Tahun 2018

\begin{tabular}{ccccc}
\hline Variabel & N & Mean & SD & P value \\
\hline $\begin{array}{c}\text { Pendokumentasian } \\
\text { asuhan keperawatan }\end{array}$ & & & & \\
$\begin{array}{c}\text { Pre test } \\
\text { Post test }\end{array}$ & 12 & 34,56 & 4,912 & 0,000 \\
& & 28,38 & 4,773 & \\
Berdasarkan tabel 13 & menunjukkan
\end{tabular}
pendokumentasian asuhan keperawatan sebelum dan sesudah diberikan supervisi, dimana rata-rata pendokumentasian asuhan keperawatan sebelum diberikan supervise 34,56 standar deviasi 4,912 yaitu tergolong tidak lengkap. Sesudah diberikan supervisi rata-rata pendokumentasian asuhan keperawatan menjadi 28,38 dengan standar deviasi 4,773 atau tergolong lengkap. Berdasarkan hasil uji statistik yang digunakan yaitu uji wilcoxon dimana data berdistribusi tidak normal didapatkan $\mathrm{P}$ value $=0,000$, maka dapat disimpulkan terdapat pengaruh supervisi dalam meningkatkan pendokumentasian asuhan keperawatan.

\section{KESIMPULAN}

1. Dari 12 responden perawat sebelum diberikan supervisi, rata-rata perkembangan pendokumentasian asuhan keperawatan sebesar 34,56 dengan standar deviasi 4,912. Selanjutnya terlihat nilai minimum 20 tergolong pendokumetasian tidak lengkap dan nilai maximum 32 tergolong pendokumentasian lengkap.

2. Dari 12 responden perawat setelah diberikan supervisi, rata-rata perkembangan pendokumentasian asuhan keperawatan sebesar 28,38 dengan standar deviasi 4,773. Selanjutnya terlihat nilai minimum 21 tergolong pendokumetasian lengkap dan nilai maximum 38 tergolong pendokumentasian lengkap.

3. Terdapat perbedaan pendokumentasian asuhan keperawatan sebelum dan sesudah diberikan supervise dengan nilai $\mathrm{P}$ Value 0,000 . 


\section{DAFTAR PUSTAKA}

Arikunto,Suharsimi.(2006),

Prosedur Penelitian: Suatu Pendekatan Praktek. Jakarta, Rineka Cipta.(2010), Manajemen Penelitian, Jakarta, Rineka Cipta.

Arwani \& Heru Supriyanto,(2006), Manajemen Bangsal Keperawatan, Jakarta, EGC

Pribadi, (2009), Analisis Pengaruh Pengetahuan, Motivasi Dan Persepsi Perawat Tentang Supervisi Kepala Ruang Terhadap Pendokumentasian Pelaksanaan asuhan Keperawatan Di RSUD Kelet Japara, Jawa Tengah.

Dalami, Ermawati (2011). Dokumentasi Keperawatan Dengan Kurikulum berbasis Kompetensi. Jakarta. Trans Info Media.

Dessley, Gray. (1997).Manajement Sumber Daya Manusia. Jilid 1.Jakarta Pt Prenhallindo .

Dinarti,\& Ratna Aryani. (2009). Dokumentasi keperawatan. Jakarta Trans InfoMedia

Etta Mamang, S \& Sopiah (2010). Metodologi Penelitian ;Pendekatan Praktis Dalam Penelitian. Jakarta. Andi Offset.

Emizar. (2009). Metodologi Penelitian

Pendidikan, Kualitatif dan Kunatitaf. Jakarta : Raja Grafindo Persada.

Hamid, A Y. (2007). Buku Ajar Riset Keperawatan.Konsep. etika,Instrument. Jakarta. EGC

Hamzah. (2011). Teori Motivasi \& Pengukuran, Edisi 8. Jakarta. Bumi Aksara.

Hyrkas K, \& Paunonen - Ilmonen M, (2001), The effects of clinical supervision on the guality of care : examining the result of team supervision, Journal of Advanved Nursing, 33(4):492-502

Ilyas. (2000). Perencanaan Sumber Daya Manusia Rumah Sakit;

Kusnanto. (2004). Pengantar Profesi \& Praktik Keperawatan Profesional. Jakarta. EGC.

Lusianah,(2008). Hubungan motivasi dan supervisi dengan kualitas dokumentasi proses keperawatan di instalasi rawat inap $R S$ Marinir Cilandak Jakarta Selatan. FIK UI

Notoatmodjo. (2002). Pengantar Pendidikan dan Ilmu Prilaku Kesehatan. Yogyakarta. Andi Offset.
Nursalam. (2011). Manajemen Keperawatan Aplikasi Dalam Praktek Keperawatan Profesional. Jakarta : Medica Salemba. (2011). Konsep dan Penerapan Metodologi Penelitian Ilmu keperawatan, Edisi 2. Selemba Medika.

Potter dan Perry. (2005). Buku ajar Fundamental Keperawatan: Konsep, Proses \& Praktik. Jakarta. EGC.

Sabri, Luknis \& Hastono.(2010). Statistik Kesehatan. Jakarta. Rajawali Pres

Sayanto.(2009). Mengenal Kepemimpinan dan Manajemen Keperawatan di Rumah Sakit. Yogyakarta. Mitra Cendikia.

Setiadi. (2012). Konsep \& Penulisan Dokumentasi Asuhan keperawatan,Teori dan Aplikasi. Yogyakarta. Graha Ilmu 